\section{O ensino de Arquitetura é uma árvore: deveria ser?}

The teaching of architecture is a tree: should be?

Bruno Cesar Euphrasio de Mello*

*Professor do Departamento de Urbanismo da Faculdade de Arquitetura da Universidade Federal do Rio Grande do Sul (UFRGS)., brunocesaremello@gmail.com usjt

\section{arq.urb}

número 30 |jan-abr de 202

Recebido: $14 / 08 / 2020$ Aceito: $12 / 03 / 2021$

\section{Palavras-chave:}

Currículo.

Composição arquitetônica.

Arquitetura.

Legislação profissional.

\section{Keywords:}

Curriculum.

Composition.

Architecture.

Professional legislation

\section{Resumo}

O presente artigo busca refletir sobre os rumos do ensino de Arquitetura e Urbanismo brasileiro neste início de século XXI. Para isso, debate seus pressupostos e contradições, recuperando o momento de constituição da Arquitetura e Urbanismo como campo autônomo, as diretrizes curriculares e a legislação profissional, indo além das experiências de renovação pedagógica. Reconhece que o ensino se organiza como árvore tendo o projeto como tronco dos currículos - e se pergunta: o ensino de arquitetura deveria ser mesmo organizado em árvore? Para responder a esta pergunta, reconstrói historicamente fatos que tornam o presente mais inteligível, pleno de desafios e dilemas.

\section{Abstract}

This article reflects on the direction of the teaching of Architecture and Urbanism in this early 21 st century. For that, it debates its assumptions and contradictions, recovering the moment of constitution of architecture as an autonomous field, the curricular guidelines and the professional legislation, going beyond the "pedagogical renewal experiences" It recognizes that teaching is organized as a tree - with the project as the trunk of the curricula - and asks itself: should architecture education really be organized in a tree? To answer this question, historically reconstructs facts that make the present more intelligible, full of challenges and dilemmas. 


\section{Introdução}

"A 'árvore' do meu título não é uma árvore verde e com folhas. Aqui, o termo 'árvore' se refere a uma estrutura abstrata".

Christopher Alexander

O início do século XXI tem desafiado o campo da Arquitetura e do Urbanismo. A pandemia e a crise econômica, particularmente no Brasil, impactaram a indústria da construção civil o que, consequentemente, acabou por reduziu a demanda por projetos arquitetônicos e urbanísticos. Mas esse estreitamento das oportunidades de trabalho não é recente, resulta também, segundo Whitaker (2011), da formação acadêmica. Segundo ele, as escolas têm, muitas vezes, relacionado o sucesso profissional ao exercício de uma arquitetura autoral de arquitetos-estrela. $O$ resultado disso é a exclusão de parte dos profissionais, já que não há espaço para todos nesse restrito nicho de mercado.

As relações laborais também sofreram transformações importantes e inéditas recentemente. O processo de Uberização (SLEE, 2017) e a nova morfologia do trabalho alcançaram o ofício de arquiteto e urbanista (MELLO et al, 2019), precarizando as relações laborais. Além disso, a era digital-financeira faz com que parte destes profissionais não controle mais a totalidade do processo de concepção de edifícios, se restringindo a desenhar fragmentos e servindo à prancheta digital como CAD-Monkeys (vendedores de sua força de trabalho como desenhistas de tarefas parciais) (ARANTES, 2012).

Algumas respostas a este quadro de mudanças têm sido vislumbradas. Segundo Montaner (2016), a virada do século tem se caracterizado pela exploração de diversas práticas alternativas. Podemos citar como exemplos a incorporação da Arquitetura informal na prática da Arquitetura erudita, as propostas de autoria coletiva de projetos, de participação da comunidade nas soluções projetuais. Estas alternativas

${ }^{1}$ Os dados que seguem foram extraídos dos sites das instituições de ensino referidas em junho de 2020. Os sites foram: UFRJ: <http://www.fau.ufrj.br/disciplinas/>. UFRGS: < http://www.ufrgs.br/ufrgs/ensino/graduacao/cursos/exibeCurso?cod_curso=300>. UFMG: têm sido o "resultado da influência, durante anos, de experiências de renovação pedagógica no ensino de arquitetura" (MONTANER, 2016, p.98).

Todo este quadro contemporâneo desafia o exercício profissional e o ensino. Como as escolas formarão profissionais arquitetos e urbanistas para enfrentar este mundo em mutação? É necessário, portanto, colocar em crise sua formação. Crise em seu sentido etimológico, de momento de decisão, de súbita mudança.

Este texto busca refletir sobre os rumos do ensino de Arquitetura e Urbanismo no século XXI, particularmente no Brasil. Para isso, debate seus pressupostos e contradições subjacentes, recuperando o momento de constituição da Arquitetura como campo autônomo, as diretrizes curriculares e a legislação profissional, indo além das "experiências de renovação pedagógica". Reconhece que ele se organiza como árvore - tendo o projeto como tronco dos currículos - e se pergunta: o ensino de arquitetura deveria ser mesmo organizado em árvore?

Para responder a esta pergunta, realiza breve historiografia que reconstrói fatos que tornam o presente - seus dilemas e desafios - mais inteligível. Não toma o aporte teórico-metodológico da historiografia por interesse diletante no passado, mas para recuperar a temporalidade de fenômenos e processos (BLOCH, 2001).

\section{Ensino como árvore}

As disciplinas de projeto constituem o tronco ou a espinha dorsal dos currículos dos cursos de Arquitetura e Urbanismo. Essa afirmação é bastante conhecida de professores e estudantes brasileiros. E é fácil reconhecer sua veracidade. Um breve e exploratório levantamento dos currículos de alguns cursos nacionais evidencia essa realidade. Vejamos, por exemplo, o que nos dizem os cursos de graduação em Arquitetura e Urbanismo da Universidade Federal do Rio de Janeiro (UFRJ), da Universidade Federal do Rio Grande do Sul (UFRGS), da Universidade Federal de Minas Gerais (UFMG), da Universidade Federal de Pernambuco (UFPE) e da Universidade de São Paulo (USP) ${ }^{1}$.

https://ufmg.br/cursos/graduacao/2372/77136>. UFPE: <https://www.ufpe.br/coord-arquitetura-eurbanismo/componentes-curriculares>. USP: <http://www.fau.usp.br/graduacao/arquitetura-eurbanismo/grade-curricular/> 
O currículo da Faculdade de Arquitetura e Urbanismo da UFRJ conta com disciplinas que abordam a composição arquitetônica/urbanística desde o primeiro semestre. E elas estão sempre entre as disciplinas com maior carga horária. № $1^{\circ}$ e $2^{0}$ semestres, as disciplinas Concepção da Forma Arquitetônica I e II têm 90 horas/aula cada. No $3^{\circ}, 4^{\circ}, 5^{\circ}$ e 6ํㅗ semestres, as disciplinas Projeto Arquitetônico têm carga horária entre 90 e 120 horas/aula. Nesses mesmos semestres estão posicionadas também as disciplinas Projeto Paisagístico (45h/a), Projeto de Interiores (90h/a) e Atelier Integrado (30h/a). No $7^{\circ}$ semestre, Projeto Urbano tem 90 horas/aula e no $8^{\circ}$, Projeto Paisagístico e Atelier Integrado II contam com 90h/a e 210h/a, respectivamente. Os dois últimos semestres concentram o Trabalho Final de Graduação.

O currículo da Faculdade de Arquitetura da UFRGS também conta com disciplinas que abordam a composição arquitetônica-urbanística do primeiro ao último semestre. E elas também estão entre aquelas com maior carga horária. As disciplinas Introdução ao Projeto Arquitetônico I e II estão posicionadas nos dois primeiros semestres do curso. Cada uma tem 135 horas/aula. Do $3^{\circ}$ ao $9^{\circ}$ semestres, se sucedem as disciplinas Projeto Arquitetônico, do I ao VII, sempre com 150 horas/aula. Do $6^{\circ}$ ao 9 o semestre, estão posicionadas as disciplinas Urbanismo I ao IV, com carga horária entre 90 e 105 horas/aula.

O currículo da Escola de Arquitetura da UFMG tem características semelhantes. Os dois primeiros semestres contam com as disciplinas Fundamentos para Projeto de Arquitetura e Urbanismo I e II, cada uma com 165 horas/aula. № $3^{\circ}$ e $4^{\circ}$ semestres, estão as disciplinas Urbanismo I e II, cada uma com 60 horas/aula. No $5^{\circ}$ semestre, está posicionada a disciplina Projeto Urbano (60h/a); no 7º, Projeto Integrado de Arquitetura e Urbanismo (120h/a); e no 9o․ Projeto Paisagístico. (25h/a). Elas são as disciplinas com maior carga horária do curso.

A centralidade do projeto arquitetônico-urbanístico - expressa pela quantidade de disciplinas a ele destinadas ao longo de todo o curso e sua expressiva carga horária - é a mesma nos currículos dos cursos de Arquitetura e Urbanismo da UFPE (onde a disciplina Projeto de Arquitetura, Urbanismo e Paisagismo ocorre do primeiro ao oitavo semestre, sendo os dois últimos semestre ocupados com disciplinas de conclusão de curso) e no da FAU-USP (onde disciplinas como Arquitetura - Projeto, Projeto da Paisagem, etc, percorrem o currículo do terceiro semestre ao fim do curso).
Subjaz ao ensino de Arquitetura e Urbanismo brasileiro, enfim, a ideia de que a formação se organiza em "árvore", cujo "tronco" que perpassa todo o currículo são as disciplinas de projeto (na escala do edifício ou da cidade). Esse pressuposto foi explicitado na década de 1940 por Lúcio Costa e permanece, 80 anos depois, como diretriz para o ensino da profissão.

\section{As bases do ensino autônomo}

Nem sempre, no Brasil, o ensino de Arquitetura e Urbanismo foi autônomo. Até aproximadamente a metade do século XX ele esteve vinculado às Escolas Politécnicas de Engenharia ou de Belas Artes. O primeiro curso tornado independente foi a Escola de Arquitetura de Belo Horizonte, em 1930 (OLIVEIRA; PERPÉTUO, 2005). Mais de uma década depois, em 1945, foi criada a Faculdade Nacional de Arquitetura no Rio de Janeiro; em 1947, a Faculdade de Arquitetura e Urbanismo do Instituto Mackenzie, desmembrada da Escola de Engenharia (STOCKLER E BREIA, 2007); em 1948, a Faculdade de Arquitetura e Urbanismo da Universidade de São Paulo, desmembrada do curso de engenheiros-arquitetos da Escola Politécnica (FICHER, 2005); e, em 1952, a Faculdade de Arquitetura da Universidade Federal do Rio Grande do Sul, fundada a partir da fusão dos cursos de Arquitetura do Instituto de Belas Artes e do de engenheiros-arquitetos da Escola de Engenharia (ROVATTI, PADÃO, 2002).

Foi nesse contexto de definição dos contornos do ensino autônomo da profissão que Lúcio Costa publicou Considerações sobre o ensino de Arquitetura (COSTA, 1949). Se esse texto não é o inaugurador, ao menos sintetiza a concepção de formação em Arquitetura que, como doutrina, orientou o perfil do ensino em todo o país. Nele, o autor defendia que a organização dos currículos deveria vincular uma "sólida formação técnico-científica" (COSTA, 1949, p.14) à consciência de que a Arquitetura "continua sendo, como no passado, fundamentalmente, arte plástica" (COSTA, 1949, p.14).

O reconhecimento da Arquitetura como Arte deveria guiar o programa de uma escola de Arquitetura. Costa (1949, p.14) definia como "inaceitável o critério proposto de tratar essa escola autônoma como uma espécie de escola de engenharia, na qual, apenas depois de um biênio fundamental comum, se passasse a cuidar de arquitetura". Neste caso, ao percorrer o currículo do curso, os que bus- 
cassem a profissão por vocação passariam por um "penoso jejum de dois anos" (COSTA, 1949, p.14).

Para Costa, o arquiteto encarava o problema da construção de maneira oposta à do engenheiro. Este último, formado no estudo das ciências exatas, enfrentaria "os problemas partindo de preferência do particular para o geral" (COSTA, 1949, p.14). $\mathrm{O}$ arquiteto, por sua vez, partiria "do conjunto para o pormenor, a fim de, então, num segundo tempo, subir do particular para o geral, de onde torna a descer, prosseguindo assim nesse vaivém" (COSTA, 1949, p.14-15). Esse modus operandi é o que fazia da Arquitetura uma Arte, e não ciência. O espírito de síntese (artístico) do arquiteto estaria em oposição ao de análise (científico) do engenheiro. Por essa razão, o ensino de ambas as profissões era diferente.

Partindo desta dualidade, Costa (1949, p.14) afirmava que a "composição 'arquitetônica' é (...) a finalidade mesma da profissão do arquiteto, é para onde convergem e onde se corporificam todas as demais disciplinas do curso, que se deverão dispor no currículo, antes do mais, em função dela" . Na composição, os diversos conhecimentos necessários à construção civil seriam relacionados, mediados, mas sempre submetidos à concepção plástica predefinida pelo arquiteto. Por isso, a composição deveria estar integrada ao cotidiano curricular discente desde o início.

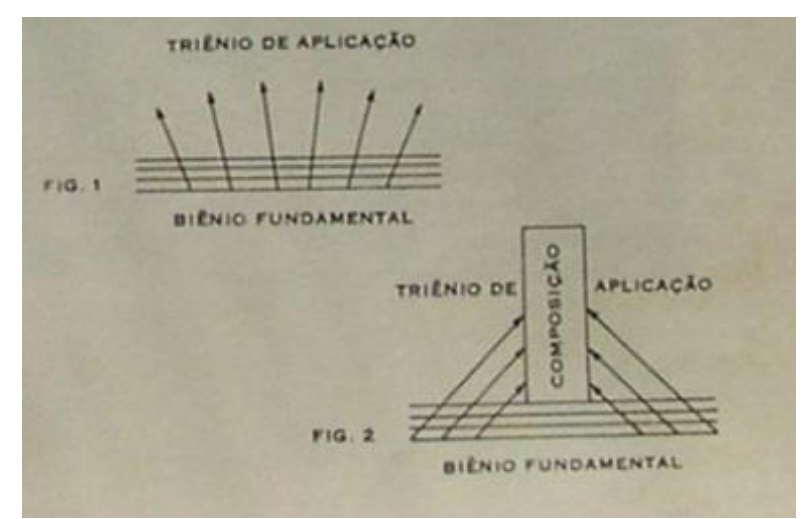

Figura Erro! Nenhuma sequência foi especificada.: Detalhe dos diagramas que sintetizam exposição de Lúcio Costa sobre as diferenças entre o ensino de arquitetura e de engenharia. Fonte: COSTA, 1949, p.15.
Como resultado da argumentação precedente, Costa (1949, p.15) afirmava o seguinte sobre o ensino de engenheiros e arquitetos:

Enquanto para os engenheiros o biênio fundamental se constitui logicamente de uma série de disciplinas teóricas indispensáveis e que vão ter a sua aplicação nos variados setores do conhecimento em que o curso se espraia, o que pode ser representado esquematicamente pela fig. 1 ; no caso dos arquitetos, visando o curso unicamente o planejamento e a construção de edifícios, todas as matérias, tanto as do biênio fundamental quanto as do triênio de aplicação, convergem para a disciplina tronco que é composição, o que se pode representar graficamente, pela fig. 2.

Fica explícita a existência de uma oposição entre o ensino de Engenharia e de Arquitetura: no primeiro, a formação seria "divergente" (linhas que se separam do biênio fundamental para o triênio de aplicação); no segundo, a formação seria "convergente" (os conhecimentos ministrados ao longo do curso convergiriam para sua aplicação prática na composição, disciplina-tronco, núcleo da formação).

\section{Composição: método e disciplina}

É notório o vínculo entre a formação oferecida pela Faculdade Nacional de Arquitetura - antiga Escola Nacional de Belas Artes carioca, onde Lúcio Costa se formou - e o modelo didático-pedagógico da École des Beaux-Arts parisiense, bem como a perenidade do método de ensino da escola francesa, sistematizado por Julien Guadet (o célebre professor de teoria da Arquitetura da École, autor de Eléments et théorie de l'Architecture), para além das fronteiras francesas (FAVERO, 2005; MACIEL, 2009).

A composição, afirma Silva (1986, p.21), conforme definida por Julien Guadet, "consolidava-se num catálogo que englobava os instrumentos e técnicas da arte de desenhar, sistemas de proporções, paredes e suas aberturas, as ordens clássicas, as plantas-tipo, tetos, escadas, cornijas, etc.". Desta forma, compor seria "combinar, em determinado projeto, elementos selecionados dentro de um repertório finito e em obediência a regras ou cânones homologados e explícitos, ainda que arbitrários ou convencionais" (SILVA, 1986, p.21). Ela era, enfim, para Guadet, “o 'artístico' da arquitetura" (KRUFT, 1990, p.507).

Vinculada à tradição acadêmica, a composição não foi superada integralmente pelo modernismo na Arquitetura. Conforme Silva (1986, p.21-22), este movimento não 
se "ocupou da renovação dos procedimentos projetuais, talvez por considerar a ideia da composição como algo permanente e inquestionável". Logo, ela se manteve como diretriz didático-pedagógica em instituições de ensino ao longo de todo século $X X$

Todavia, a composição a que Costa se referia não se reduz à seleção e combinação de elementos físicos. É também um processo mental de articulação de campos disciplinares variados - sejam eles de caráter tectônico, científico, social, cultural - que "convergiriam" para a concretização da obra arquitetônica. A composição, enfim, não seria só de formas, volumes, planos, mas também um modo particular de articulação entre conhecimentos variados, o que só poderia ocorrer nas disciplinas de composição arquitetônica (ou de projeto, diríamos hoje).

A disciplina composição - e não só o método compositivo - seria, por consequência, o centro da formação em Arquitetura. Ela representa o momento em que o estudante exercitaria as competências necessárias ao domínio operativo da síntese arquitetônica. Por isso, ela funcionaria como o "tronco" ou a "espinha dorsal" da formação em Arquitetura. Essa maneira de dar centralidade à composição (como método e como disciplina curricular) guiou o ensino de Arquitetura nas décadas subsequentes. $E$ isso fica claro quando avaliamos as iniciativas de currículo mínimo da década de 1960. É o que será apresentado a seguir.

\section{Diretrizes curriculares}

O que dizem as diretrizes curriculares acerca da centralidade do projeto na formação do arquiteto e urbanista? Este trabalho não realizará uma historiografia dos currículos mínimos e das diretrizes curriculares. A apresentação de apenas alguns deles será suficiente para expressar $\mathrm{o}$ argumento aqui delineado.

A primeira referência a um currículo mínimo nacional de Arquitetura é de 1962 , quando foi aprovado, em 17 de novembro, o parecer no 336 do Conselho Federal de Educação (CONSELHO FEDERAL DE EDUCAÇÃO, 1962). Esse currículo buscava 'impedir a 'fragmentação' da formação profissional em áreas especializadas e defendeu o aprimoramento e o preparo do arquiteto em setores específicos por meio de atividades complementares" (CONFEA, 2010, p.65).

As disciplinas que representavam o mínimo curricular eram as seguintes: Cálculo; Física Aplicada; Resistência dos Materiais e Estabilidade das Construções;
Desenho e Plástica; Geometria Descritiva; Materiais de Construção; Técnica de Construção; História da Arquitetura e da Arte; Teoria da Arquitetura; Estudos Sociais e Econômicos; Evolução Urbana; Legislação, Prática Profissional e Deontologia; Composição (Arquitetônica, de Interiores e de Exteriores); Planejamento.

Apesar dessa diversidade de conteúdos, o parecer expunha que a formação profissional deveria se centrar

na Composição Arquitetônica, da Composição de Interiores, da Composição de exteriores e do Planejamento, com o objetivo de desenvolver as aptidões de imaginação, de sensibilidade, de bom senso e a coordenação de todos os fatores chamados a intervir na realização de obra, recomendando-se que o tempo destinado a essa prática compreenda parte substancial da duração do Curso (CONSELHO FEDERAL DE EDUCAÇÃO, 1962).

Os demais conteúdos teriam finalidade assessória. As disciplinas "culturais" (história da arte, da arquitetura, sociologia, organização social, evolução urbana, economia e política, estudos brasileiros) deveriam ser consideradas "como meios e não fins de ensino" (CONSELHO FEDERAL DE EDUCAÇÃO, 1962). As técnicas-científicas de aplicação direta (cálculo, mecânica, resistência dos materiais e estabilidade das construções, sistemas estruturais), os sistemas e métodos de construção (técnicas e materiais de construção, física, higiene e saneamento) e os meios de expressão (desenho, plástica, geometria descritiva, perspectiva, topografia) deveriam ser orientados "em sentido instrumental com vistas à aplicação da prática das composições e dos planejamentos" (CONSELHO FEDERAL DE EDUCAÇÃO, 1962).

Percebe-se que a concepção de ensino que vinha sendo construída desde a década de 1940, expressa nas Considerações sobre o ensino de Arquitetura, de Lúcio Costa, é reafirmada neste currículo mínimo: a centralidade da composição, a submissão dos demais conteúdos - como "meios, não fins" ou com "sentido instrumental" - orientados à aplicação na prática de composição.

Poucos anos depois, em 1969, foi definido novo currículo mínimo de Arquitetura. Foi o parecer no $384 / 69$, da Comissão Especial do Conselho Federal de Educação, que opinou sobre o currículo mínimo, aprovado em 6 de maio daquele ano. Ele se fundamentou no princípio de que a forma "é antecedente e consequente: preside à formulação em atendimento aos requisitos funcionais e aos elementos construtivos" (ABEA, 1977, p.71-72). A forma era primordial. "Tudo se funde na forma, a qual, 
porém, continua a ser a preocupação do arquiteto, tão simples e natural como se não existisse em si mesma" (ABEA, 1977, p.72), afirmava o parecer.

Mais uma vez, a forma (revelada por meio da elaboração de um projeto) deveria presidir a formação do arquiteto e submeter outras dimensões. A comissão especial definiu ainda, nas observações, que no currículo mínimo o projeto "constituirá a atividade criativa aplicada, quer quanto à arquitetura das habitações e edifícios em geral, quer quanto a projetos de objetos (arquitetura interior), quer quanto a cidades e regiões (planejamento urbano e regional)" (ABEA, 1977, p.74).

Enfim, o currículo mínimo de 1969 não alterou os pressupostos da formação em Arquitetura já manifestos em 1962.

Apresentados os currículos mínimos da década de 1960, base da regulação do ensino de Arquitetura e Urbanismo brasileiro, façamos um salto temporal. O que diz a atual regulamentação do ensino? Referir-nos-emos apenas, como conclusão desta parte do artigo, às diretrizes curriculares nacionais para o curso de bacharelado em Arquitetura e Urbanismo atualmente em vigor, segundo Resolução nํㅜ 2, de 17 de junho de 2010, do Ministério da Educação.

O artigo $3^{\circ}$ dessa resolução refere que a proposta pedagógica para os cursos brasileiros deverá assegurar "a formação de profissionais generalistas" (MINISTÉRIO DA EDUCAÇÃO, 2010). O artigo 5을 define que os cursos devem possibilitar, ao futuro egresso, competências e habilidades para, dentre diversos outros aspectos: i) conhecer aspectos antropológicos, sociológicos e econômicos; ii) compreender ações de preservação da paisagem e avaliação de impactos ambientais, com vistas ao desenvolvimento sustentável; iii) conceber projetos de arquitetura, urbanismo e paisagismo, considerando fatores como custo, durabilidade, etc.; iv) conhecer a teoria e história das artes, arquitetura, urbanismo; v) dominar técnicas e métodos para elaboração de planos urbanos, metropolitanos e regionais; vi) empregar adequada e economicamente sistemas estruturais, materiais de construção e técnicas construtivas, definir instalações prediais, organizar canteiros; vii) preservar, conservar, restaurar edifícios ou conjuntos históricos.

Essa pequena lista, destacada das diretrizes curriculares nacionais, denota a diversidade de vieses do exercício profissional que a atual formação em Arquitetura e
Urbanismo deveria contemplar. Ao menos nas diretrizes curriculares, a centralidade do projeto, existente na década de 1960, já não é uma imposição tão categórica. Por que razão ela permanece nos currículos?

Essa mesma dispersão das atividades possíveis de serem exercidas profissionalmente por Arquitetos e Urbanistas está expressa na atual regulamentação profissional. Vejamos a seguir.

\section{Atual regulamentação profissional}

A Lei 12.378, que criou o Conselho de Arquitetura e Urbanismo (CAU), foi sancionada em 2010. Ela definiu um amplo rol de campos de atuação. São eles, por exemplo, conforme seu artigo 2º, a concepção e execução de Arquitetura, Urbanismo, Interiores, Paisagismo; restauro, preservação e conservação do patrimônio histórico, cultural e artístico; Planejamento Urbano e Regional, metropolitano; elaboração e interpretação de levantamentos topográficos cadastrais; da tecnologia da construção, patologias e recuperações; dos sistemas construtivos e estruturais; das instalações e infraestruturas; do meio ambiente, estudo e avaliação de impactos ambientais, licenciamento ambiental, etc.

O arquiteto e urbanista é, segundo esse texto, um profissional generalista que está habilitado para exercer uma gama ampla e multifacetada de atividades. A formação dá conta dessa diversidade?

Mas essa pluralidade gera a sobreposição de campos de atuação com outras profissões, como a Engenharia, por exemplo. E para definir claramente quais são as atividades compartilhadas e quais são privativas de arquitetos e urbanistas, o Conselho de Arquitetura e Urbanismo aprovou, em 2013, a Resolução n 51 . O preâmbulo dessa resolução antecipa que ela foi construída a partir da identificação de um problema que

há décadas [os arquitetos e urbanistas] vêm assistindo várias das atividades técnicas que historicamente foram reconhecidas como de sua alçada - projeto arquitetônico, urbanístico e paisagístico, e aquelas do âmbito do patrimônio histórico sendo indevidamente exercidas por outros profissionais que não têm a necessária formação acadêmica que os credencie para tal (CAU, 2013). 
Importante destacar que o Conselho dá atenção às atividades "reconhecidas" como sendo próprias do arquiteto e urbanista: fundamentalmente, o projeto, em qualquer escala. E é essa atribuição profissional que o CAU pretende que não seja exercida "indevidamente" por outros profissionais.

Foi com a Lei 12.378/10 que "se apresentaram em plenitude as condições para a efetiva individualização da Arquitetura e Urbanismo e para sua diferenciação em relação às demais profissões regulamentadas" (CAU, 2013). O esforço de delimitação das atividades específicas do arquiteto e urbanista representaria também o esforço para caracterizar a "personalidade" da profissão.

Apesar de não recuperar os termos de Costa, a Resolução no 51 acompanha as premissas expostas na década de 1940 em Considerações sobre o ensino de Arquitetura - a de que o arquiteto e urbanista é o profissional capaz de realizar a síntese arquitetônica, expressa pelo processo de projeto. Para além da busca de uma identidade, a Resolução $n^{\circ} 51$ é também uma maneira complementar de distinguir a formação (e as capacidades) do arquiteto e urbanista daquelas do engenheiro. Há, associada à definição de uma identidade profissional, uma disputa corporativa pelo domínio da elaboração de certos produtos da construção civil - notadamente, o projeto nas mais variadas escalas (dos interiores ao espaço urbano).

Apesar da Resolução no 51 indicar a existência de um "núcleo" caracterizador da atividade profissional, a lei que criou o CAU, por sua vez, apresenta o arquiteto e urbanista como um profissional bastante polivalente. Como o ensino de Arquitetura e Urbanismo pode, ao mesmo tempo, espelhar a diversidade de campos de atuação e o "núcleo" da atividade centrada no projeto? Não existiria aí certa hesitação, por parte do Conselho, sobre o que é atuar como arquiteto e urbanista no Brasil? A Resolução ${ }^{\circ} 51$ não representa certo "conservadorismo" acerca do que é o exercício - e, finalmente, o ensino - da Arquitetura e Urbanismo? As diretrizes e bases nacionais da educação em Arquitetura e Urbanismo parecem ser mais radicais no alargamento dos fazeres dos arquitetos e urbanistas. Baseado nessas posições e contradições, não seria hora de repensar as bases e os pressupostos do ensino?

\section{Considerações finais}

O ensino de Arquitetura é uma árvore: deveria ser?

Este artigo afirmou, no início, que o ensino de Arquitetura e Urbanismo é organizado em "árvore". Mas será que a formação e o exercício da profissão deveriam ser mesmo estruturados de tal forma ainda hoje? Que alternativas poderia haver?

Como pressuposto, o ensino deveria pautar-se por três aspectos: i) a diversidade de atividades passíveis de serem exercidas profissionalmente por arquitetos e urbanistas, conforme o artigo $2^{\circ}$ da Lei 12.378/10 (a qual criou o CAU); ii) a formação de profissionais generalistas, segundo indicam as diretrizes curriculares nacionais, expressando toda a diversidade de habilidades e competências referidas no artigo 5 da Resolução no 2, de 17 de junho de 2010, do Ministério da Educação; iii) a livre escolha discente de construir sua formação e sua futura trajetória profissional de acordo com seu perfil, personalidade e interesses. Mas como fazer isso?

Uma resposta possível talvez esteja na própria formulação de Costa, explicitada nos diagramas que sintetizam as diferenças entre o ensino de Arquitetura e Engenharia (Figura 1). Seria possível pensar uma mudança de perspectiva: uma formação em Arquitetura mais "divergente" (linhas que se separam de uma base fundamental comum para um período final de direcionamento em eixos de atuação profissional), ao invés de uma "convergente" (todos os conhecimentos submetidos à composição).

Essa hipótese alteraria radicalmente a estrutura de ensino vigente no país desde pelo menos o processo de autonomia ocorrido na década de 1940. Diluiria a centralidade da composição e reconheceria que hoje o exercício da Arquitetura e Urbanismo contempla diversas atividades que não se submetem ou esgotam na síntese do projeto/composição. Manteria a unidade na profissão, mas permitiria a diversificação. Afinal, de que valem as habilidades e competências para a síntese arquitetônica ou para a composição quando o arquiteto e urbanista é convocado para gerenciar obras? Ou para construir técnica e politicamente um plano de cidades ou regiões?

Não resolveria, certamente, todos os dilemas da profissão. Mas apontaria novos caminhos para a formação e o exercício profissional no século XXI. 


\section{Referências}

ABEA. Associação Brasileira de Escolas de Arquitetura. Sobre a história do ensino de Arquitetura no Brasil. São Paulo: Abea, 1977.

ARANTES, Pedro Fiori. Arquitetura na era digital-financeira: desenho, canteiro e renda da forma. São Paulo: Editora 34, 2012.

BRASIL. Lei $n^{\circ}$ 12.378, de 31 de dezembro de 2010. Regulamenta o exercício da Arquitetura e Urbanismo; cria o Conselho de Arquitetura e Urbanismo do Brasil CAU/BR e os Conselhos de Arquitetura e Urbanismo dos Estados e do Distrito Federal - CAUs; e dá outras providências. Disponível em: <http:/www.planalto.gov.br/ccivil_03/_ato2007-2010/2010/lei/12378.htm>. Acessado em: 04 fev. 2020.

BLOCH, Marc. Apologia da História, ou, O ofício do historiador. Rio de Janeiro: Zahar, 2001.

CONFEA. Trajetória e estado da arte da formação em engenharia, arquitetura e agronomia: Volume $\mathbf{X}$ - Arquitetura e Urbanismo. Brasília, DF: CONFEA, INEP, 2010.

CONSELHO DE ARQUITETURA E URBANISMO DO BRASIL. Resolução n ${ }^{\mathbf{5 1}}$, de 12 de julho de 2013. Dispõe sobre as áreas de atuação privativas dos arquitetos e urbanistas e as áreas de atuação compartilhada com outras profissões regulamentadas, e dá outras providências. Disponível em: <http://www.caubr.gov.br/wpcontent/uploads/2012/07/RES51-2013ATRIB-PRIVATIVAS20-RPO-1.pdf>. Acessado em: 04 fev. 2020.

CONSELHO FEDERAL DE EDUCAÇÃO. Currículo mínimo do curso de arquitetura e urbanismo. Parecer no 336. Aprov. em 17-11-1962. [s.l.], 1962. 2f.

COSTA, Lucio. Considerações sobre o ensino da arquitetura. ESPAÇO: Revista de Arquitetura-Urbanismo- Arte. Porto Alegre: Organizado por um grupo de alunos do IBA, ano 1, n.3, jun., 1949. p.14-15.

FÁVERO, Marcos Osmar. Dos mestres sem escola à escola sem mestres: ensino de arquitetura no Rio de Janeiro - 1816-1965. Tese (doutorado) - Universidade Federal do Rio de Janeiro, Faculdade de Arquitetura e Urbanismo, Rio de Janeiro, 2009.
FICHER, Sylvia. Os arquitetos da Poli: Ensino e Profissão em São Paulo. São Paulo: Fapesp: Editora da Universidade de São Paulo, 2005.

KRUFT, Hanno-Walter. História de la teoria de la arquitectura. Vol.2. Desde el siglo XIX hasta nuestros dias. Madrid, Espanha: Alianza Editorial, 1990.

MACIEL, Ângela Becker. Iniciação ao ensino do projeto arquitetônico: paradigmas e reducionismos. Tese (doutorado) - Universidade Federal do Rio Grande do Sul, Faculdade de Arquitetura, Porto Alegre, 2009.

MELLO, Bruno C. E., KUHN, Eugenia A., RORATO, Geisa Z., D'OTTAVIANO, Maria C. L. Trabalho e exercício profissional do arquiteto-urbanista brasileiro. In: Asociación de Escuelas Y Facultades Públicas de Arquitectura de América del Sur, 2019, Belo Horizonte. Anais eletrônicos... Campinas, GALOÁ, 2019. Disponível em: <https://proceedings.science/arquisur-2019/papers/trabalho-e-exercicio-profissional-do-arquiteto-urbanista-brasileiro?lang=pt-br>. Acesso em: 05 mai. 2020.

MINISTÉRIO DA EDUCAÇÃO. Conselho Nacional de Educação, Câmara de Educação Superior. Resolução no 2, de 17 de junho de 2010. Disponível em: $<$ http://portal.mec.gov.br/index.php?option=com_docman\&view=download\&alias=5651-rces002-10\&category_slug=junho-2010-pdf\&ltemid=30192>. Acessado em: 04 abr. 2020.

MONTANER, Josep Maria. A condição contemporânea da arquitetura. São Paulo: Gustavo Gili, 2016.

OLIVEIRA, Cléo Alves Pinto de; PERPÉTUO, Maini de Oliveira. O ensino na primeira escola de arquitetura do Brasil. Arquitextos. São Paulo, ano 06, n. 066.04, Vitruvius, nov. 2005. Disponível em: <http://www.vitruvius.com.br/revistas/read/arquitextos/06.066/408>. Acessado em: 04 fev. 2020.

ROVATTI, João Farias; PADÃO, Fabiano Mesquita (orgs). Faculdade de Arquitetura: 1952 - 2002. Porto Alegre: Gráfica da UFRGS, Faculdade de Arquitetura, 2002.

SILVA, Elvan. Sobre a renovação do conceito de projeto arquitetônico e sua didática. In: COMAS, Carlos Eduardo Dias (org.). Projeto arquitetônico disciplina em crise, disciplina em renovação. São Paulo, Projeto, 1986. 
SLEE, Tom. Uberização: a nova onda do trabalho precarizado. São Paulo: Elefante, 2017.

STOCKLER E BREIA, Maria Teresa de. 0 ensino de arquitetura na faculdade de arquitetura do Mackenzie: Do beaux-arts ao moderno (1947-1965). In:GITAHY, Maria Lúcia Caira; LIRA, José Tavares Correia de (orgs.). Tempo, cidade e arquitetura. São Paulo: Annablume: FAUUSP: FUPAM, 2007.WHITAKER, João Sette. "Perspectivas e desafios para o jovem arquiteto no Brasil. Qual o papel da profissão?" Arquitextos. São Paulo, ano 12, n. 133.07, Vitruvius, jul. 2011. Disponível em:<http://www.vitruvius.com.br/revistas/read/arquitextos/12.133/3950>. Acessado em: 04 fev. 2020. 